\title{
Discussion on the Installation of Safety Action Failure Warning System in the Power Supply System of Beijing Winter Olympic Games
}

\author{
Guo Chunping \\ Shanxi Quan'an New Technology Development Company Ltd., Taiyuan, China
}

\section{Emailaddress:}

gcp.007@163.com

\section{To cite this article:}

Guo Chunping. Discussion on the Installation of Safety Action Failure Warning System in the Power Supply System of Beijing Winter Olympic Games. Science Discovery. Vol. 9, No. 2, 2021, pp. 43-46. doi: 10.11648/j.sd.20210902.14

Received: March 10, 2021; Accepted: April 12, 2021; Published: April 16, 2021

\begin{abstract}
The 2022 Beijing Winter Olympic Games is the first Winter Olympic Games that China has applied to host. It not only symbolizes the strength of China's sports cause, but also shows the strength of China's national strength. In order to ensure a safe and reliable power supply for the Beijing Winter Olympics, this paper analyzes the possible shortcomings of anti-violation in"three protection", "throw protection", technical standards of the power supply system of Beijing 2022 Winter Olympic Games, listed the fire accident lessons of Ice and Snow Museum of Taitai mountain in Taiyuan, and puts forward the method of the Winter Olympic Games to make up the"short board of anti-violation". For example, adding action failure warning system to the powe rsupply system, working with technical experts, making up the short board of anti-violation to prevent and resolving the professional risks of illegal electrical. At the same time, the paper puts forward some technical ideas to prevent the violation of regulations, which will add a layer of insurance for the power guarantee and safe electricity consumption of the Winter Olympic Games.
\end{abstract}

Keywords: Beijing Winter Olympics, Safety Protection, Failure Warning, Anti-violation

\section{在北京冬奥会供电系统加装安全保护动作失灵预警系统探讨}

\section{郭春平}

山西全安新技术开发有限公司, 太原, 中国

\section{邮箱}

gcp.007@163.com

摘要: 2022年北京冬奥会是我国申请举办的第一次冬季奥运会, 它对于我国来说不仅象征着体育事业的强大, 更显示 了中国的国力之强盛。文章分析了2022年北京冬奥会供电系统“三大保护”、“甩保护”、技术标准可能存在的抗违章短 板, 列举了太原台骀山冰雪馆火灾事故教训, 提出了在冬奥会供电系统加装安全保护动作失灵预警系统、与技术专家 合作、补齐抗违章短板防范和化解违章电气专业风险的技术等补齐“抗违章短板”的方法, 并提出了防范违章技术思路, 为冬奥会电力保障和安全用电再加上一层保险。

关键词: 北京冬奥会, 安全保护, 失灵预警, 抗违章 


\section{1. 引言}

2022年北京冬奥会是我国申请举办的第一次冬季奥 运会, 它对于我国来说不仅象征着体育事业的强大, 更显 示了中国的国力之强盛。目前, 北京冬奥会各项筹备工作 进展顺利。1月20日,习近平

总书记在北京人民大会堂主持召开北京2022年冬奥 会和冬残奥会筹办工作汇报会并发表重要讲话，从 2 月 4 日起，进入北京冬奥会倒计时。习近平总书记在听取汇报 后对推进赛会服务保障提出明确要求,其中特别强调：“安 全是重大体育赛事必须坚守的底线”[1]。

作为北京2022年冬奥会和冬残奥会官方合作伙伴的 国家电网表示: 实现智慧供电, 确保冬奥会保障范围内电 网设备的安全稳定运行, 实现设备零故障, 工作零差错, 用户零闪动, 服务零距离, 实现安全高效、智能开放和冬 奥会 $99.9999 \%$ 高可靠供电目标。北京冬奥会如何保证 99.9999\%高可靠供电目标? 笔者认为：必须补齐“抗违章 短板”, 否则, 高可靠性目标无法实现。

\section{2. 北京冬奥会供电系统存在抗违章短板}

据调查, 北京冬奥会共有 12 个竞赛场馆, 其中北京赛 区共6个竞赛场馆, 分别为国家速滑馆、首钢滑雪大跳台、 国家游泳中心、五棵松体育中心、国家体育馆和首都体育 馆; 延庆赛区竞赛场馆共 2 个, 分别为国家高山滑雪中心、 国家雪车雪㲕中心; 张家口赛区竞赛场馆共 4 个, 分别为 国家跳台滑雪中心、国家越野滑雪中心、国家冬季两项中 心、云顶滑雪公园。这些场馆的供电系统都客观存在方便 作业人员进行违章作业的“硬原因”，即“抗违章短板”[2] 或称作“误操作短板”[3]。

\section{1. 北京冬奥会 12 个场馆供电系统“三大保护”存在抗违 章短板}

供电系统的短路、漏电和保护接地三大保护的共同特 点是在发生电气故障后才断电跳闸 [4-5], 除一些具有绝缘 监视功能的漏电保护外, 大部分保护不能在发生电气故障 前实现断电或报警以预控事故发生[6]。绝缘监视的基本原 理是实时检测供电网络系统的绝缘电阻值, 当绝缘电阻降 低到预警界数值时报警提示[7], 因为绝缘电阻进一步降低 可能引起漏电故障, 所以具有一定漏电故障预警功能 [8]。 但是, 在违章或误操作接近带电体造成电火花之前: 绝缘 电阻不会降低, 绝缘监视装置就不会报警提示; 短路、漏 电电流或电压没有产生, 短路、漏电保护也不会动作保护; 没有形成接地故障, 保护接地也不起作用。所以, 北京冬 奥会 12 个场馆供电系统的三大保护都起不到超前预控违 章带电作业作用, 只能在违章带电作业造成短路、漏电和 接地故障后起到保护作用, 也就是说存在抗违章短板。

\section{2. 北京冬奥会12个场馆供电系统存在“倡保护”抗违章 短板}

电气作业人员轻易地违章操作（如: 擅自或误调整 定值), 就能使供电系统保护功能失效或动作灵敏度降
低, 一旦发生短路、漏电故障时, 供电系统短路和漏电 保护不能可靠地动作保护, 从而造成严重事故。这是由 于供电系统没有预控违章“甩保护”的技术装备或监控系 统 [9], 没有“甩保护”后闭锁而不能送电功能, 也没有把 “甩保护”信息自动发送给电气安全监管人员的风险预警 系统，作业人员“甩保护”后供电系统可“带病”供电。这 就是供电系统存在的可轻易违章的“甩保护”抗违章短板 [10]。

\section{3. 北京冬奥会 12 个场馆供电系统技术标准存在的抗违 章短板}

有关技术标准都为电压、温度等“物”的因素制定了技 术要求, 在出厂时进行耐压、耐高温试验, 试验合格才能 出厂。[11-12]但北京冬奥会12个场馆供电系统的抗违章技 术标准很少，几乎没有试验当“人”出现“违章”（包括误操 作）等非理性行为时, 供电系统能否通过技术手段来预防 违章作业而保证设备正常工作的技术标准, 更没有考虑智 能设备由于“中毒”等原因而发生“违章”作业会导致什么 后果。

\section{3. 事故教训}

去年10月 1 日太原台骀山冰雪馆导致人员伤亡的重大 火灾事故, 就是由于相关设备无漏电保护且短路保护失灵 不动作（即“甩保护”），导致在违章带负荷操作隔离开关 而造成短路时, 不能自动跳闸切断故障电源而造成的。这 一事故的惨痛教训是十分深刻的, 冬奥会供电系统也有短 路保护和漏电保护, 还有温度、速度、压力等多种安全保 护设施, 这些短路保护和漏电保护都可能因违章包括误操 作等原因造成动作失灵而造成事故[13-15]同时, 为确保场 馆供电系统要达到高可靠性供电目标, 还要必须预防故意 违章行为发生。

\section{4. 补齐“抗违章短板”的方法}

\section{1. 加装短路/漏电等安全保护动作失灵预警系统的方法}

在冬奥会供电系统加装安全保护动作失灵预警系统, 为冬奥会电力保障和安全用电再加上一层保险。

\section{2. 与技术专家合作}

邀请技术发明人、专利申请单位与国家电网和华为等 单位联合制定技术方案, 并召开技术研讨会讨论技术方案 的可行性及必要性。该技术已在山西全安公司实验室试用 一年多，最近在山西焦煤集团试用。

\section{3. 补齐抗违章短板防范和化解违章电气专业风险的技 术}

据检索，国内这方面的技术还十分缺少，所以，各个 国家只能通过“人防”降低违章电气专业风险。可用“4 $\mathrm{G} / 5 \mathrm{G}$ 智能短路漏电保护”动作失灵手机风险预警系统提高安全 风险。 


\subsection{1. 感知供电系统保护工作状态}

$4 \mathrm{G} / 5 \mathrm{G}$ 智能短路/漏电保护动作失灵手机风险预警系 统(见图1), 具有 $5 \mathrm{G}$ 或 $4 \mathrm{G}$ 通讯功能, 能将线路开关的工作 状态和电气综合保护装置的保护运作状态上传到云平台, 推送到手机端APP; 可以实时监测短路保护、漏电保护等 安全保护装置的“投入”或“退出”; 还能实时监测线路开关
的分合闸状态、电压值和电流值等电气参数, 远程控制上 级电源开关的电气综合保护装置实现分、合闸操作; 配置 报警断电关系，不用增加线路，可报警或切断数千米至数 百千米外的上级电源开关，实现报警、断电或闭锁; 对违 章甩保护造成线路开关实整值与规整值不符等违章操作, 进行报警提示。
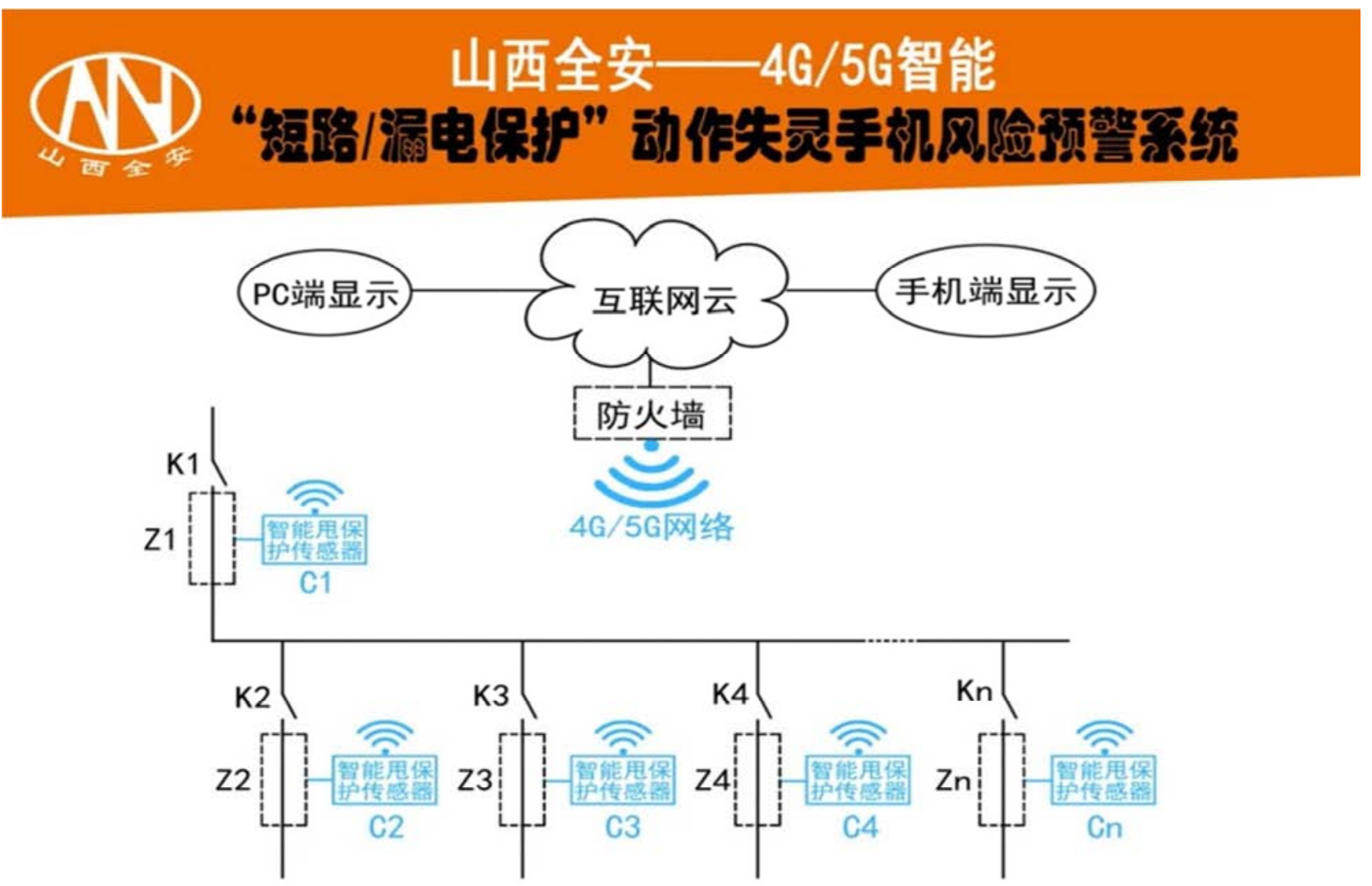

一、说明:

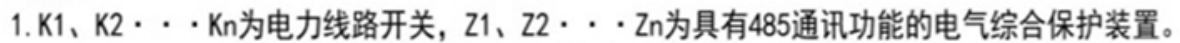

$2 . C_{1} 、 C \cdots C_{n}$ 为智能甩保护传感器, 可感知短路保护或漏电保护是否被甩。有5G或 4 G 通讯功能。

3. 该 “智能甩保护传感器” 已获国家专利 “一种安全保护装置的智能检测方法及装置”，专利号: 201910776441. 3。

二、功能

通讯功能: 具有56或46通讯功能, 能将线路开关的工作状态和电气综合保护装置的保护运作状态上传到云平台, 推送到手 机端APP。

保护运作状态监测功能: 实时监测短路（速断）保护、漏电保护、过电压保护、低电压保护、过流保护，过载保护及相不 平衡保护的 “投入” 或 “退出”，及人为甩保护。

测控功能: 实时监测线路开关的分合闸状态，线路电压、电流、电量及保护定值、参数，控制电气综合保护装置实现线路

开关的分、合闸操作。

预警功能：对甩保护、线路开关实整值与规整值不符等违章操作进行报警提示，或配置断电关系，进行断电、闭锁。

三、指标

供电电源: DC12V。

无线参数: $5 G$ 或 $4 G$, 全网通。

通讯接口: 一路RS485端口, 本安信号输出。

图1 短路/漏电保护动作失灵手机风险预警系统图。

\subsection{2. 感知谁在打开供电装置门（盖）}

供电装置门 (盖) 安装监控传感器, 专职维护人员通 过输入工号及密码打开供电装置的门（盖）, 传感器向监
控中心传送人员姓名、时间，警示专职维护人员不可随意 甩保护或私自调整短路、漏电保护动作值参数。非专职维 护人员不知开门 (盖) 密码、打不开门 (盖), 如果强行 打开, 则现场和监控室同时发出声光报警。 


\subsection{3. 点检功能}

点检功能也叫巡更功能, 就是要求维护电工定时对配 电装置进行巡回检查, 由安装在配电装置上的接收器记录 维护电工巡回检查的时间, 从而避免漏检、假检 (不开门 盖）。

\subsection{4. 检修闭锁功能}

当维护电工需要停电检修时, 在需要停电的配电装置 上设置停电检修密码。只有输入正确密码才能打开门盖进 行送电, 如果输入密码错误, 首先是打不开门盖, 其次是 现场和监控室声光报警; 如果违章强行打开门盖, 则自动 切断该配电装置的上级电源并闭锁不能送电, 并且现场和 监控室声光报警。

\subsection{5. 其他功能}

经过扩充, 还可监控温度、压力、速度等各种安全保 护设施的工作状态。

\section{5. 防范违章技术思路}

长期以来, 国内外都是通过宣传、培训、教育、管理、 法律等“人海战术”防治违章作业, 并取得了很大成效。但 不可否认的事实是：迄今为止，违章仍然是造成90\% 95\% 事故的主要原因。这一客观存在的事实告诉我们, 宣传、 培训、教育、管理、法律等方法都存在一定的局限性。这 些方法的共同之处是，对违章行为立足于“人防”，侧重于 “治”，结果却是防不胜防。而我们所倡导推广应用的抗违 章理论及其技术，对违章行为却是立足于“技防”及“智（能） 防”，侧重于“控”或“预警”，通过相应的技术手段，在尚未 造成事故后果的违章过渡过程中, 把违章行为动作控制在 危险的违章红线以外或超前预警。

\section{6. 结语}

习近平总书记关于冬奥会筹备工作的重要讲话, 科 学研判了当前筹办工作面临的风险挑战, 明确提出了需 要扎实抓好的重点工作, 为我们做好下步工作指明了前 进方向、提供了根本遵循。我们一定要切实把思想行动 统一到总书记重要讲话精神上来, 坚守安全这一底线, 补齐冬奥会供电系统的“抗违章短板”, 确保冬奥会安全 供电万无一失。

\section{参考文献}

[1] 习近平.在考察北京2022年冬奥会和冬残奥会筹办工作时 的讲话[Z].2021.

[2] 郭春平.抗违章技术创新方法研究[J].煤矿安全，2010年05期.

[3] 杨泓,李刚,韩建军,等.城市配电网规划及存在问题分析 [J]. 内蒙古电力技术, 2009,27(5):1-5.

[4] 姜霏.浅析矿山供电系统漏电保护[J].河北煤炭, 2005年05 期.

[5] 煤矿安全规程[S].煤炭工业出版社, 2004.

[6] 贾猛.井下低压电网漏电保护分析[J].煤矿机械, 2004年09期.

[7] 王建涛,娄石.交流不间断电源系统绝缘报警分析及监视方 法改进[J].低压电器, 2010年05期.

[8] 变电站直流电源系统绝缘电阻检测技术的研究与应用 [J]. 信息技术与信息化, 2017年第12期.

[9] 褚文超,张燕飞,李英俊,鲁耀.城市电网供电可靠性影响因素 分析及措施[J].内蒙古电力技术,2016,34(01):19-24.

[10] (美)霍罗威茨帕德凯.电力系统继电保护(原书第3版)[M].李 斌, 译.机械工业, 2010年10期.

[11] 李长海, 关瑞利, 李道本, 王素英.北京奥运典型场馆供电 系统分析[J].电气应用, 2010年07期.

[12] 徐惠妍.2010广州亚运会场馆变配电系统改造分析[J].电气 时代, 2010年11期.

[13] 李雪岩.体育场馆设施电气多功能方案分析与改造[J].农村 电气化, 2019 年 07 期.

[14] 王素军, 徐金栋. 简谈体育场馆工艺供配电[J].建筑电气, 2020年09期.

[15] 黄伟, 范宪铭济南奥体中心主场馆供电可靠性分析[J].山东 电力技术, 2010 年 03 期.

\section{作者简介}

郭春平, 山西全安公司董事长、国务院特贴专家、正高 级电气工程师、山西省政协委员, “4 $\mathrm{G} / 5 \mathrm{G}$ 智能短路漏电 保护”动作失灵手机风险预警系统发明人, 